\title{
$\mathrm{CoCrFeMnNi}$ 고엔트로피 합금에서 탄소 첨가 및 재결정열처리가 미세구조 및 기계적 특성에 미치는 영향 \\ 고준영 · 송재숙 · 홍순익* \\ 충남대학교 신소재공학과
}

\section{Effect of Carbon Addition and Recrystallization on the Microstructure and Mechanical Properties of CoCrFeMnNi High Entropy Alloys}

\author{
Jun Yeong Ko, Jae Sook Song, and Sun Ig Hong* \\ Department of Materials Science and Engineering, Chungnam National University, Daejeon 34134, Republic of Korea
}

\begin{abstract}
The effect of carbon addition on the cast and rolled microstructures of CoCrFeMnNi high entropy alloys were studied. Both as-cast $\mathrm{CoCrFeMnNi}$ and $\mathrm{CoCrFeMnNiC}_{0.1}$ alloys have a dendritic microstructure. Small carbide particles were observed at the inter-dendritic region in the as-cast $\mathrm{CoCrFeMnNiC}_{0.1}$ and elongated-grained structure with aligned carbides were developed at grain boundaries in $\mathrm{CoCrFeMnNiC}_{0.1}$ after homogenization. The grain size decreased from $9.2 \mu \mathrm{m}$ to $5.8 \mu \mathrm{m}$ with the addition of $0.1 \mathrm{wt} \%$ carbon. The decrease in grain size is due to its high stored cold work energy during deformation processing, resulting in more active recrystallization in $\mathrm{CoCrFeMnNiC}_{0.1}$ and the pinning effect of carbides. The strengthening in $\mathrm{CoCrFeMnNiC}_{0.1}$ is most likely attributed to solid solution strengthening and nanoscale carbide strengthening, because grain size strengthening was found to be not as effective.
\end{abstract}

(Received May 23, 2017; Accepted September 25, 2017)

Keywords: high entropy alloys, carbon, interstitial, CoCrFeMnNi, carbide

\section{1. 서 론}

최근 주 원소에 소량의 다른 합금 원소가 첨가되는 기존 합금과는 달리 4,5 원계 이상의 합금 원소가 비슷한 비율 로 혼합됨에도 불구하고 단상을 이루는 고엔트로피 합금들 이 많은 관심을 받고 있다 [1-11]. 고엔트로피 합금은 금 속간화합물 형성과 관련된 자유에너지 감소보다 여러 원소 의 혼합에 의한 배열 엔트로피의 증가의 영향이 우세하여 전체 자유에너지를 감소시킴으로써, 다성분 원소들 간 금 속간화합물이나 제 2상을 형성하기 보다는 여러 원소가 혼 합된 고용체가 형성되는 합금이다.

고엔트로피 합금은 5 내지 $35 \mathrm{at} \%$ 사이의 원자 농도를 갖는 5 종 이상의 금속 성분을 함유하며 첨가된 모든 원소 가 주 원소로서 작용하는 합금 시스템으로 합금 내의 유사 한 원자분율로 인하여 높은 혼합 엔트로피가 유발되고, 따

*Corresponding Author: Sun Ig Hong [Tel: +82-42-821-7637, E-mail: sihong@cnu.ac.kr] Copyright (C) The Korean Institute of Metals and Materials
라서 고온에서 안정한 간단한 구조의 고용체를 형성한다. 고엔트로피 합금들에 대한 구조와 특성에 있어서 성분금속 들의 영향에 대한 연구가 광범위하게 진행되고 있으며, 다 양한 합금원소들로 구성된 고엔트로피합금들의 연구결과가 발표되고 있다 [1-4]. 대부분의 고엔트로피합금들의 연구는 치환형 고용체를 형성시키는 합금원소들로 이루어져 있으 며, 침입형 합금원소들로 구성되는 고엔트로피 합금에 대 한 연구는 많은 관심을 갖지 못하였다.

대표적인 고엔트로피합금은 Oxford대학의 Cantor에 의하 여 연구된 $\mathrm{CoCrFeMnNi}$ 고엔트로피 합금으로 특히 극저 온에서 높은 연성을 나타내며, 오스테나이트강의 기계적 특 성과 많은 유사성을 나타낸다. 고엔트로피 합금에 영향을 미치는 인자로는 격자변형, 확산, cocktail효과, 고엔트로피 등이 있다 [5]. 이러한 인자들 중에서 격자변형은 기계적 특성을 향상시킬 수 있으며, 침입형 합금원소의 첨가 시 격자변형은 치환형 합금 원소 첨가보다 커서 기계적 특성 증가에 효과적이다 [10-14]. 탄소는 강에서 침입형 합금 원 소로 작용하며 상 조성과 특성에 많은 영향을 미친다. 최근 
Stepanov 와 연구진은 [1] 탄소가 첨가된 $\mathrm{CoCrFeMnNiC}_{0.1}$ 고 엔트로피 합금의 주조조직에서 나노 크기의 탄화물을 관찰 하였으며, $\mathrm{CoCrFeMnNiC} \mathrm{C}_{0.1}$ 고엔트로피 합금 주조재의 기 계적 특성에 대한 연구에서는 기계적 쌍정에 의하여 strain hardening rate(강화 속도)와 강도를 증가시키는 것으로 나 타났으나, 탄소 첨가 고엔트로피 합금의 가공 후의 특성 및 미세구조에 대한 결과는 아직 밝혀지지 않은 부분이 많 다. Stepanov 등 [1]은 $\mathrm{HEA}$ 의 적층결함에너지는 스테인리 스 스틸의 경우처럼 탄소 첨가에 의하여 적층결함에너지가 증가한다고 가정하고 회복이 쉽게 일어난다고 보고한 반 면, $\mathrm{Wu}$ 등 [6]은 탄소 첨가에 의하여 쌍정의 형성 빈도가 높아짐을 관찰하였고, 이는 탄소 첨가에 의해 적층결함에 너지가 감소함을 나타낸다고 제안하였다.

고엔트로피합금에서의 탄소 첨가 효과에 의한 쌍정형성 및 적층결함에너지에 대한 Stepanov의 해석 [1]은 $\mathrm{Wu}$ 의 해석 [6]과 상반되며, 쌍정 및 적층결함에 대한 효과는 $\mathrm{HEA}$ 의 변형거동 및 특성 분석에 중요한 인자이므로, 고 엔트로피합금에서의 탄소효과에 대한 정밀 분석이 필요하 다. 특히 Stepanov [1]는 탄소가 첨가되지 않은 고엔트로 피 합금을 같이 주조하여 탄소 영향을 분석하지 않고, 문 헌에 보고된 탄소가 첨가되지 않은 고엔트로피 합금의 결 과와 자신들이 탄소 첨가하여 제조한 합금과의 특성을 비 교하여, 그들의 분석이 다른 공정의 영향을 배제한 분석 인지는 확신하기 어렵다. 따라서 본 연구에서는 Cantor 합금을 기본으로 한 $\mathrm{CoCrFeMnNi}$ 고엔트로피 합금에 탄 소를 첨가한 합금과 첨가하지 않은 합금을 제조하고 똑 같은 주조 및 압연, 열처리을 시행하여, 다른 열처리 및 가공 공정의 차이를 배제하고, 탄소의 첨가가 주조 조직, 가공 조직 및 기계적 특성에 미치는 영향을 분석하였다.

\section{2. 실험방법}

탄소 첨가의 영향을 분석하기 위하여 합금용해는 순금속을 이용하여 진공아크용해로에서 equi-atomic $\mathrm{CoCrFeMnNi}$ 과 $0.1 \mathrm{wt} \%$ 의 탄소가 $\mathrm{CoCrFeMnNiC}_{0.1}$ 을 진공용해 하였다. 진 공용해시 진공도는 10-5 torr로 유지하였으며, 버튼 모양으 로 주조된 잉곳은 합금성분들이 균일하게 분포되도록 앞/

Table 1. Composition of the alloys investigated in the present study.

\begin{tabular}{c|c|c|c|c|c|c}
\hline \multicolumn{1}{|c}{ Alloy } & Fe & Co & Cr & Ni & Mn & C \\
\hline FeCoCrNiMn & 20 & 20 & 20 & 20 & 20 & \\
\hline FeCoCrNiMnC & 20 & 20 & 20 & 20 & 20 & 0.1 \\
\hline
\end{tabular}

뒤로 바꾸면서 5 회 반복 용해하였다. 주조된 버튼 모양의 잉곳은 아르곤 분위기에서 $1,050{ }^{\circ} \mathrm{C}$ 에서 24 시간 균질화처 리 하였으며, 상온에서 압연 공정을 통하여 판상의 형태로 가공하였다. 압연 시 최종 가공율은 $84 \%$ 로 최종 판재두께 는 $1.2 \mathrm{~mm}$ 였다. 판상으로 가공된 시편을 이용하여 표점거 리가 $9 \mathrm{~mm}$ 인 인장시편을 방전가공을 통하여 압연 방향에 평행한 방향으로 가공하였다. 인장시험은 상온에서 $10-3 \mathrm{~s}^{-1}$ 의 변형속도로 실시하였으며, 미세구조는 질산 $1 \mathrm{ml}+$ 염 산 $3 \mathrm{ml}$ 의 용액에서 20 초 간 에칭한 후 광학현미경과 $\mathrm{EDS}$ 가 장착된 주사전자현 미경 (JEOL JSM-5410)을 이용 하여 분석하였다.

\section{3. 결과 및 고찰}

고엔트로피 합금의 탄소 첨가가 주조재의 미세구조에 미치 는 영향을 분석하기 위하여 $\mathrm{CoCrFeMnNi}$ 합금과 $\mathrm{CoCrFeMnNiC}_{0.1}$ 합금의 주조 후 미세조직을 관찰하였으며 그림 1 에 나타내었다. 그림에서 보여주는 바와 같이 $\mathrm{CoCrFeMnNi}$ 합금과 $\mathrm{CoCrFeMnNiC}_{0.1}$ 합금 모두 덴드라 이트 구조를 나타낸다. 탄소가 첨가되지 않은 합금은 불규 칙한 형태의 덴드라이트가 형성되는 반면 (그림 1(a)), 탄 소가 첨가된 $\mathrm{CoCrFeMnNiC}_{0.1}$ 합금의 경우 그림 $1(\mathrm{~b})$ 에 서 보여주는 것처럼 덴드라이트 가 규칙적으로 형성되었다 (primary dendrite는 파선, secondary dendrite는 점선으로 그림 우측 상단에 표시). 특이한 점은 secondary dendrite $\mathrm{arm}$ 사이에 미세한 입자 (검은 화살표) 들이 존재한다. 이 는 응고 시의 다른 합금원소와 마찬가지로 첨가된 탄소가 $\mathrm{Cr}$ 탄화물을 형성하여 응고 시의 편석되어 석출되기 때문 이다. 탄화물이 interdendritic region에 석출되어 dendrite $\mathrm{arm}$ 에 평행하게 분포하는 현상은 다른 합급계에서 많이 관 찰되었다 [7,8]. $\mathrm{CoCrFeMnNiC}_{0.1}$ 합금의 경도는 $155.3 \mathrm{Hv}$ 로 측정되어 탄소가 첨가되지 않은 $\mathrm{CoCrFeMnNi}$ 합금의 경도 $152.6 \mathrm{Hv}$ 보다 약간 높게 측정되었다. $\mathrm{CoCrFeMnNi}$ 합금과 $\mathrm{CoCrFeMnNiC}_{0.1}$ 합금의 경도 차이가 크지 않은

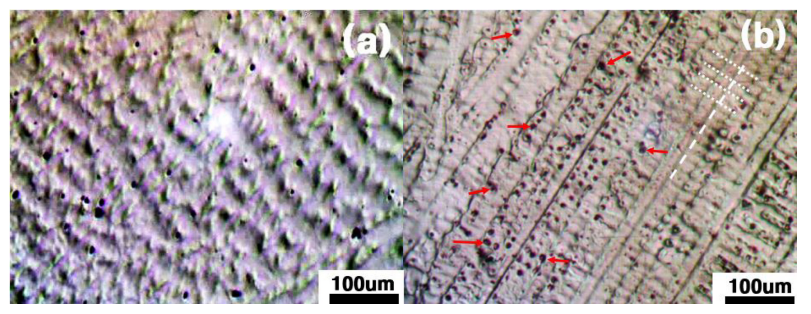

Fig. 1. Optical micrographs of the as-solidified FeCoCrNiMn (a) and $\mathrm{FeCoCrNiMnC}_{0.1}$ (b) alloys 


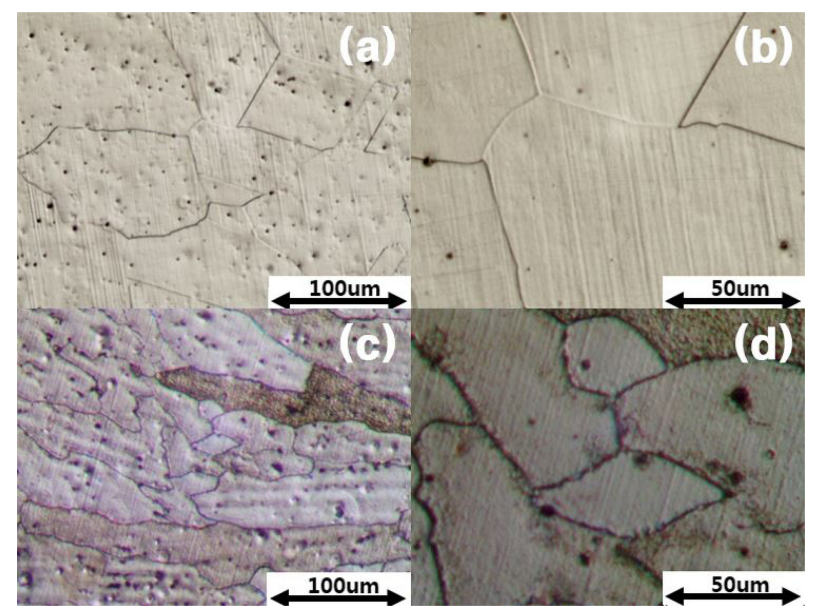

Fig. 2. Optical micrographs of the FeCoCrNiMn and $\mathrm{FeCoCrNiMnC}_{0.1}$ alloys homogenized at $1,050^{\circ} \mathrm{C}$ for $24 \mathrm{hrs}$. FeCoCrNiMn (a, b), FeCoCrNiMnC 0.1 (c, d).

것은 주조 동안에 발생한 탄소나 탄화물들이 편석되어 존 재하기 때문으로 여겨진다.

그림 2 는 $1,050{ }^{\circ} \mathrm{C}$ 에서 24 시간 균질화 처리한 $\mathrm{CoCrFeMnNi}$ 합금과 $\mathrm{CoCrFeMnNiC} 0.1$ 합금의 미세구조를 보여준다. 그림에서 보여주는 바와 같이 $\mathrm{CoCrFeMnNi}$ 합금 과 $\mathrm{CoCrFeMnNiC}_{0.1}$ 합금 모두 균질화 처리 후 덴드라이 트 구조가 사라진 것을 볼 수 있으며, 탄소가 첨가된 $\mathrm{CoCrFeMnNiC}_{0.1}$ 합금의 경우 연신된 결정립 구조로 바뀌 었다. 이와 같은 연신된 결정립 구조는 주조 시에 interdendritic region에 편석된 탄화물과 연관이 되어 있을 가 능성이 크다. 그림 $2(\mathrm{c}, \mathrm{d})$ 에서 보여주는 바와 같이 연신 된 결정립의 긴 축은 배열된 탄화물에 의해 성장/이동이 억제되므로, 주조 후 dendrite 가 잘 발달했던 부위는 inter-dendritic region에 석출된 던 탄화물에 의해, dendrite arm에 수직한 방향으로의 결정립 성장이 억제되 어, 결정립이 등축정이 아니라 연신되어 보인다. $\mathrm{CoCrFeMnNi}$ 합금의 결정립의 크기 $133.9 \mu \mathrm{m}$ 이며, $\mathrm{CoCrFeMnNiC}$. 1 합금에서 탄화물들이 결정립계에 편석되어 결정립의 성장을 방해하여 연신된 결정립이 형성되며 $\mathrm{CoCrFeMnNiC}_{0.1}$ 길이 방향의 장축과 단축을 random하게 평 균낸 결정립 크기는 $95.3 \mu \mathrm{m}$ (연신된 방향으로의 결정립 크 기는 $139.6 \mu \mathrm{m}$, 수직한 단축 방향의 크기는 $51.1 \mu \mathrm{m}$ )로 관 찰되어 탄소가 첨가되지 않은 $\mathrm{CoCrFeMnNi}$ 합금의 경우보다 작게 관찰된다. $\mathrm{CoCrFeMnNiC}$. 립계에 편석되어 결정립의 성장을 방해하기 때문에 결정립 크기는 $\mathrm{CoCrFeMnNi}$ 합금보다 작게 관찰된다.

그림 3 은 $1,050^{\circ} \mathrm{C}$ 에서 24 시간 균질화 처리한 $\mathrm{CoCrFeMnNiC} \mathrm{C}_{0.1}$

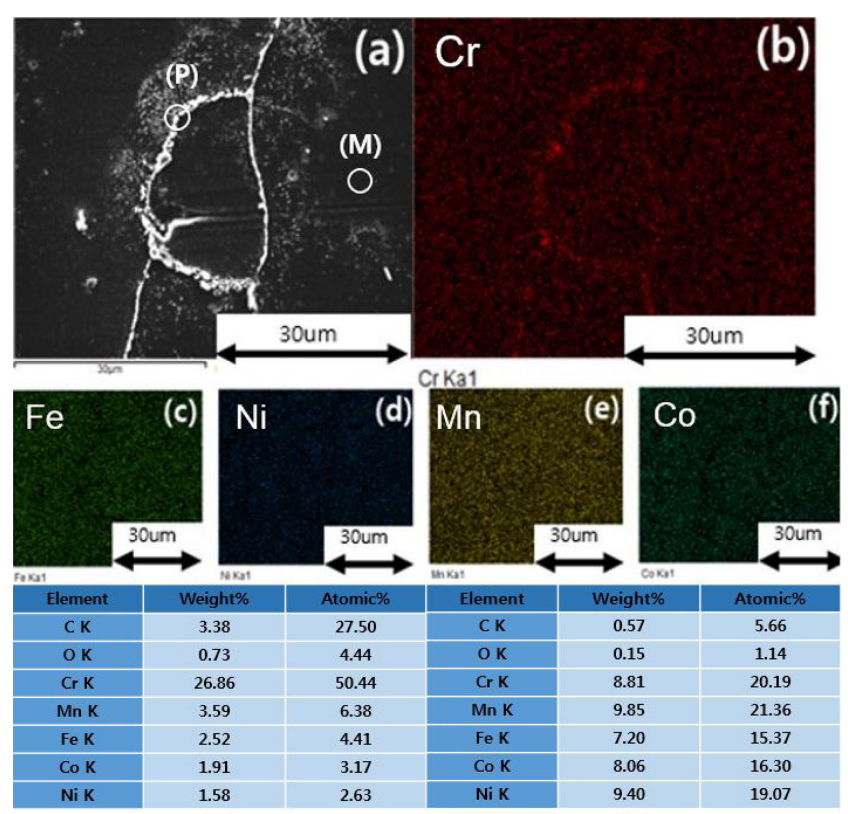

(g)

(h)

Fig. 3. EDS of the $\mathrm{FeCoCrNiMnC}_{0.1}$ alloy homogenized at $1323 \mathrm{~K}$ for $24 \mathrm{~h}$.

a) SEM image , b) composition obtained from the points marked $P$, c) composition obtained from the points marked $\mathrm{M}$

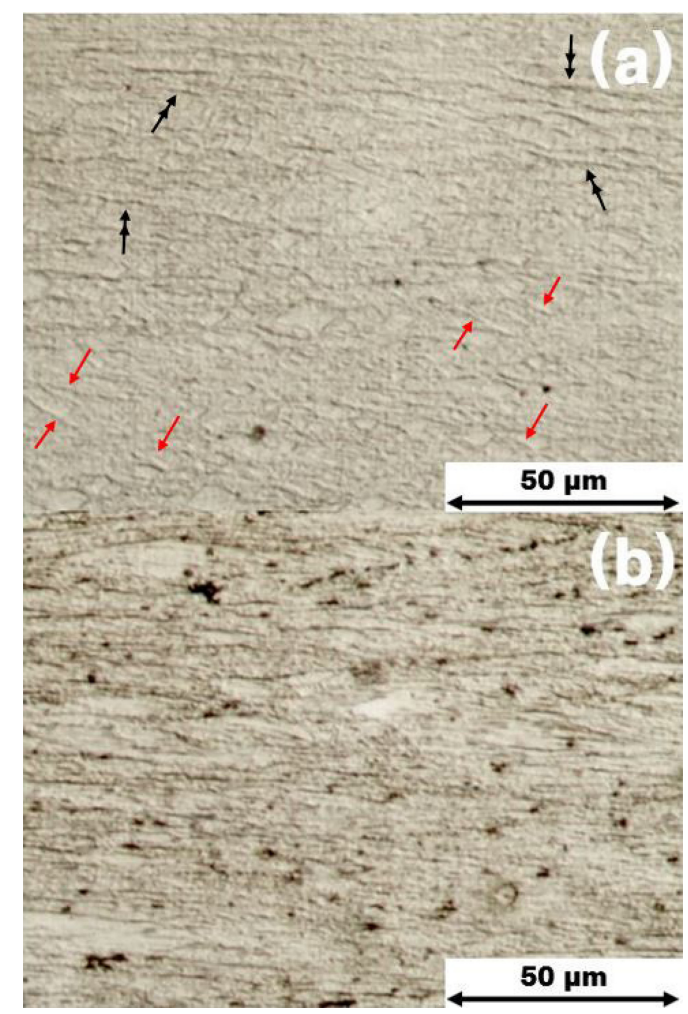

Fig. 4. Optical micrographs of the FeCoCrNiMn and FeCoCrNiMnC 0.1 alloys homogenized at $1,050^{\circ} \mathrm{C}$ for $24 \mathrm{hrs}$ and rolled at room temperature with the reduction ratio of $\sim 84 \%$. FeCoCrNiMn (a), FeCoCrNiMnC 0.1 (b) 
합금의 SEM 이미지 (3(a))와 Mapping 이미지 (3(b) 3(f)) 를 보여준다. 그림 $3(\mathrm{a})$ 에서 보여 주는 바와 같이 결정립 계에 석출물이 존재함을 알 수 있다. Mapping 이미지 (3(b) 3(f))에서, $\mathrm{Fe}, \mathrm{Ni}, \mathrm{Mn}, \mathrm{Co}$ 는 전 지역에서 비교적 균등하게 분포하는 반면, $\mathrm{Cr}$ 은 결정립계 근체에서 농도가 높아짐을 보여준다. 결정립계에 존재하는 석출물(그림 3(a) 에 $\mathrm{P}$ 로 표시된 위치)과 기지(그림 3(a)에 $\mathrm{M}$ 으로 표시된 위치)에서의 조성을 그림 $3(\mathrm{~g})$ 와 $3(\mathrm{~h})$ 에 각각 나타내었다. 그림 기지 내의 $\mathrm{M}($ 그림 $3(\mathrm{~g}))$ 위치에서는 Mapping 이미 지에서와 마찬가지로, $\mathrm{Cr}, \mathrm{Fe}, \mathrm{Mn}, \mathrm{Co}, \mathrm{Ni}$ 이 골고루 분 포하며 탄소가 미량 관찰된 반면, 결정립계의 $\mathrm{P}($ 그림 $3(\mathrm{~g}))$ 위치에서는 $\mathrm{Cr}$ 과 $\mathrm{C}$ 이 주 성분을 이루는 것으로 보아, 결 정립계에는 탄소가 포함된 $\mathrm{Cr}$ 탄화물이 존재하는 것으로 판단된다.

그림 4는 $\mathrm{CoCrFeMnNi}$ 합금과 $\mathrm{CoCrFeMnNiC}_{0.1}$ 합금 을 $1,050{ }^{\circ} \mathrm{C}$ 에서 24 시간 균질화 처리 후 상온에서 $84 \%$ 의 가공율로 냉간압연한 후의 미세구조를 보여준다. 그림에서 화살표로 표시한 바와 같이 $\mathrm{CoCrFeMnNi}$ 합금은(그림 $4 \mathrm{a}$ ) 냉간가공 중에 발달한 deformation band(변형밴드)가 관찰 되나 $\mathrm{CoCrFeMnNiC}_{0.1}$ 합금은(그림 $4 \mathrm{~b}$ ) 변형밴드가 관찰되 지 않고 $\mathrm{Cr}$ 탄화물의 미세한 입자들이 균일하게 분포된 압연방향으로 길게 늘어난 가공조직이 형성되었음을 알 수

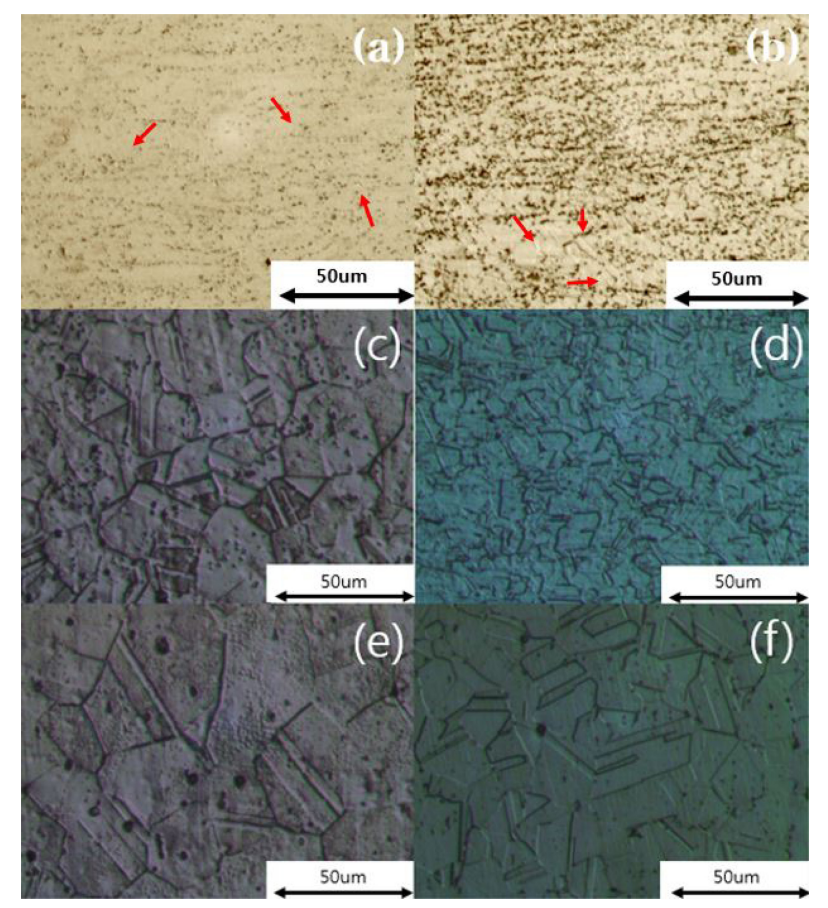

Fig. 5. Optical micrographs of the FeCoCrNiMn (a, c, e) and $\mathrm{FeCoCrNiMnC}_{0.1}$ (b, d, f) alloys after cold rolling and subsequent annealing at $800^{\circ} \mathrm{C}(\mathrm{a}, \mathrm{b}), 900^{\circ} \mathrm{C}(\mathrm{c}, \mathrm{d}), 1000^{\circ} \mathrm{C}(\mathrm{d}, \mathrm{f})$ for $2 \mathrm{hrs}$.
있다. 이는 $\mathrm{Cr}$ 탄화물이 변형밴드의 전파 및 성장을 방해 하는 것으로 해석된다.

그림 5 는 $\mathrm{CoCrFeMnNi}$ 합금 (a)와 $\mathrm{CoCrFeMnNiC}_{0.1}$ (b) 합금을 상온에서 $84 \%$ 의 가공율로 가공 후 $800^{\circ} \mathrm{C}$, $900{ }^{\circ} \mathrm{C}, 1,000^{\circ} \mathrm{C}$ 에서 2 시간 열처리 후의 시편의 미세구조 를 보여준 다. 그림에서 보여 주는 바와 같이 $800{ }^{\circ} \mathrm{C}$ 에서 2시간 열처리한 $\mathrm{CoCrFeMnNi}$ 합금 (그림 5a)은 미세한 결 정립들이 불균일하게 생성/성장되었으며 (화살표로 표시), 냉간 가공 중 발달한 변형밴드는 관찰되지 않는다. $800{ }^{\circ} \mathrm{C}$ (그림 5b)에서 열처리된 탄소첨가 $\mathrm{CoCrFeMnNiC}_{0.1}$ (b) 합 금도 $\mathrm{CoCrFeMnNi}$ 합금과 마찬가지로 미세한 결정립들이 (화살표) 생성되었으며, 이러한 결정립들은 $\mathrm{CoCrFeMnNi}$ 합 금보다 균일하게 분포하고 있음을 알 수 있다. 그림 5(a) 와 5(b)에 화살표로 표시한 바와 같이 작은 결정립과 twin 밴드는 일부 구역에서만 명확하게 관찰되는데, 이는 $800{ }^{\circ} \mathrm{C}$ 에서는 국부적인 재결정이 일어나며, 따라서 전반적인 재 결정을 위해서는 더 높은 온도에서 열처리해야 됨을 나타 낸다. 그림 $5(\mathrm{c}) \sim 5(\mathrm{f})$ 는 $\mathrm{CoCrFeMnNi}$ 합금 $(\mathrm{c}, \mathrm{e})$ 과 $\mathrm{CoCrFeMnNiC}_{0.1}$ (d, f) 합금을 $900^{\circ} \mathrm{C}(\mathrm{c}, \mathrm{d})$ 와 $1,000{ }^{\circ} \mathrm{C}$ $(\mathrm{e}, \mathrm{f})$ 에서 재결정 열처리한 미세조직을 보여주고 있다. 그 림에 나타난 바와 같이, 탄소가 첨가되지 않은 $\mathrm{CoCrFeMnNi}$ 합금의 twin boundary(쌍정계면) 포함 결정 립 크기는 $900{ }^{\circ} \mathrm{C}$ 열처리 후 $9.2 \mu \mathrm{m}$ (그림 5(c))이고 $1000{ }^{\circ} \mathrm{C}$ 열처리 후 $15.7 \mu \mathrm{m}$ (그림 $5(\mathrm{e})$ )로 측정되어 온도 가 증가함에 따라 결정립이 커지고 미세한 입자들의 분포 가 감소한다. 탄소가 첨가된 $\mathrm{CoCrFeMnNiC}_{0.1}$ 합금도 $900{ }^{\circ} \mathrm{C}$ (그림 $\left.5 \mathrm{~d}\right)$ 와 $1,000{ }^{\circ} \mathrm{C}$ (그림 $5 \mathrm{f}$ ) 열처리 재결정에 의 하여 결정립 과 twin 밴드 구조가 관찰되며, 쌍정계면 포 함 결정립 크기는 $900{ }^{\circ} \mathrm{C}$ 에서 $5.8 \mu \mathrm{m}$ 이고 $1000{ }^{\circ} \mathrm{C}$ 에서 $9.3 \mu \mathrm{m}$ 로 측정되어 온도가 증가함에 따라 결정립이 커지 고 미세한 입자들의 분포는 감소하고 있다. 탄소가 첨가된 $\mathrm{CoCrFeMnNiC}_{0.1}$ 합금이 $\mathrm{CoCrFeMnNi}$ 합금보다 열처리에 따른 결정립의 크기가 작게 관찰되며, 이는 탄소 또는 탄 화물이 결정립 감소의 직접적인 원인임을 의미한다.

본 연구에서 탄소첨가한 $\mathrm{CoCrFeMnNiC} 0.1$ 합금에서의 $\mathrm{CoCrFeMnNi}$ 합금 대비 결정립 크기의 감소는 탄소 첨가 가 결정립 크기에 영향을 미치지 않는다는 Stepanov 등 [14]의 보고와 다른 결과이다. 그러나 Stepanov 등 [14]은 탄소의 영향을 관찰하기 위해 다른 연구자 [14-16] 들이 다 른 조건에서 가공된 시편의 결과를 서로 비교한 것이므로 결과의 신뢰도가 떨어지며, 본 연구에서는 같은 조건에서 주조하고 같은 조건으로 가공한 시편에서의 결과이므로 탄 소 첨가에 의해 결정립크기가 감소한다는 본 연구의 결과 


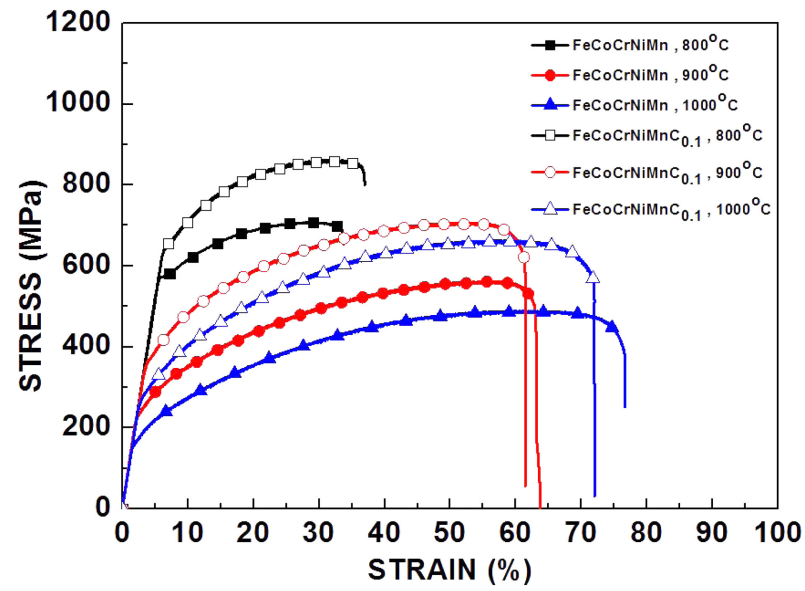

Fig. 6. Representative engineering stress-strain curves of the FeCoCrNiMn and FeCoCrNiMnC ${ }_{0.1}$ after cold rolling and subsequent annealing at $800{ }^{\circ} \mathrm{C}, 900{ }^{\circ} \mathrm{C}, 1000{ }^{\circ} \mathrm{C}$ for $2 \mathrm{hrs}$.

가 Stepanov 등 [14]의 결과보다 신뢰도가 높은 결과이다. 탄소 첨가 $\mathrm{CoCrFeMnNiC}$. 합금에서의 결정립 크기 감소 는 그림 4 에 나타낸 바와 같이 가공 중 탄소첨가에 의한 dynamic recovery (동적 회복) 속도 감소에 의한 냉간가공 에너지 증가 [17,18] 및 그림 3에 나타낸 바와 같이 탄화 물의 결정립 성장의 pinning 효과 때문인 것으로 판단된다. Hong 등 $[17,18]$ 은 탄소 첨가한 경우, 전위에 segregation 이 일어나 cross slip이나 climb 을 어렵게 하여 회복속도 를 늦추기 때문에 전위밀도가 높아지며, 따라서 냉간가공 에너지 축적이 증가한다고 제안하였다. 그림 4에서와 같이 $\mathrm{CoCrFeMnNiC}_{0.1}$ 합금에서 냉간가공에너지의 증가에 의한 가공조직이 발달하는 경우, 재결정 열처리 시에 핵생성이 활발해지고, 일부 탄화물이 결정성장을 제어하여 결정립 크 기가 감소하는 것으로 해석할 수 있다.

그림 6 은 $\mathrm{CoCrFeMnNi}$ 합금과 $\mathrm{CoCrFeMnNiC}_{0.1}$ 합금 을 냉간압연 후 $800{ }^{\circ} \mathrm{C}, 900{ }^{\circ} \mathrm{C}, 1,000{ }^{\circ} \mathrm{C}$ 에서 2 시간 열처리 후 인장시험한 응력-변형율 곡선을 나타낸다. 그림에서 보는 바와 같이 $800{ }^{\circ} \mathrm{C}$ 에서 열처리한 경우 탄소가 첨가된 $\mathrm{CoCrFeMnNiC}_{0.1}$ 합금의 항복강도와 인장강도는 각각 632 $\mathrm{MPa}, 850 \mathrm{MPa}$ 로 측정되었으며, 탄소가 첨가되지 않은 $\mathrm{CoCrFeMnNi}$ 합금의 항복강도와 인장강도는 각각 $568 \mathrm{MPa}$, $703 \mathrm{MPa}$ 로 측정되어 탄소가 첨가된 $\mathrm{CoCrFeMnNiC}_{0.1}$ 합금의 강도가 높게 측정되었다. 또한 탄소가 첨가된 $\mathrm{CoCrFeMnNiC}_{0.1}$ 합금의 연신율은 $28 \%$ 로 측정되었으며, 탄 소가 첨가되지 않은 $\mathrm{CoCrFeMnNi}$ 합금의 연신율은 $26 \%$ 로 측정되어 탄소가 첨가된 $\mathrm{CoCrFeMnNiC} 0.1$ 합금의 연신율이 약간 높게 관찰되었다. $900{ }^{\circ} \mathrm{C}$ 에서 열처리한 경우 탄소가 첨가되지 않은 $\mathrm{CoCrFeMnNi}$ 합금의 항복강도와 인장강도
는 $224 \mathrm{MPa}, 562 \mathrm{MPa}$ 로 측정되었으며, 탄소가 첨가된 $\mathrm{CoCrFeMnNiC}_{0.1}$ 합금의 항복강도와 인장강도는 361 $\mathrm{MPa}, 706 \mathrm{MPa}$ 로 측정되었다. $1,000{ }^{\circ} \mathrm{C}$ 에서 열처리 시 탄소가 첨가되지 않은 $\mathrm{CoCrFeMnNi}$ 합금의 항복강도와 인 장강도는 $154 \mathrm{MPa}, 480 \mathrm{MPa}$ 로 측정되었고, 탄소가 첨 가된 $\mathrm{CoCrFeMnNiC}_{0.1}$ 합금의 항복강도와 인장강도는 $255 \mathrm{MPa}, 663 \mathrm{Mpa}$ 로 측정되었다.

각 온도에서의 열처리 후 항복강도와 인장강도가 차이에 서 나타난 바와 같이 고엔트로피합금의 가공경화속도가 크 다는 것을 알 수 있다. 그림 6 에서 $900{ }^{\circ} \mathrm{C}, 1,000^{\circ} \mathrm{C}$ 에서 열처리 후에는 항복강도가 낮고 가공경화율이 큰 반면에, $800{ }^{\circ} \mathrm{C}$ 에서 열처리한 경우에는 항복강도가 낮고 특히 탄소 가 첨가되지 않은 $\mathrm{CoCrFeMnNi}$ 합금의 경우 가공경화율 이 많이 감소하였음을 보여준다. 이는 $800{ }^{\circ} \mathrm{C}$ 에서 열처리 한 경우에는 그림 5 에 나타난 바와 같이, 재결정이 부분적 으로 형성되어, 국부적으로 전위밀도가 높은 구역이 많아 항복강도가 높고 가공경화율이 감소함을 알 수 있다. 탄소 가 첨가된 $\mathrm{CoCrFeMnNiC}$. 리 한 경우에도 가공경화율이 높은데, 이는 앞에서 설명한 바와 같이 탄소 첨가가 회복율을 감소시켜, 가공경화능을 증 가시키기 때문이다 [17-23]. 그림 6에서 탄소가 첨가되지 않 은 $\mathrm{CoCrFeMnNi}$ 합금과 탄소가 첨가된 $\mathrm{CoCrFeMnNiC}{ }_{0.1}$ 합금의 가공경화율이 크게 차이가 나지 않는 것은 탄소의 첨가가 전위 이동의 방해물로 마찰 응력으로 작용하기 때 문이다 $[19,21,24,25]$.

탄소가 첨가된 $\mathrm{CoCrFeMnNiC}_{0.1}$ 합금의 연신율은 $63 \%$ 로 측정되었으며, 탄소가 첨가되지 않은 $\mathrm{CoCrFeMnNi}$ 합 금의 연신율은 $65 \%$ 로 측정되어 탄소가 첨가되지 않은 $\mathrm{CoCrFeMnNi}$ 합금의 연신율이 크게 측정되었다. 모든 열 처리 온도에서 탄소가 첨가된 $\mathrm{CoCrFeMnNiC}$..1 합금의 강 도가 탄소가 첨가되지 않은 $\mathrm{CoCrFeMnNi}$ 합금의 강도 보 다 높게 측정되었다. 즉 탄소가 첨가된 $\mathrm{CoCrFeMnNiC}{ }_{0.1}$ 합금은 탄소가 첨가되지 않은 $\mathrm{CoCrFeMnNi}$ 합금에 비하 여 미세한 입자가 균일하게 분포하며, 결정립 크기가 미세 하기 때문에 높은 강도를 나타내는 것으로 여겨진다. 연신 율은 $800{ }^{\circ} \mathrm{C}$ 시 열처리시 탄소가 첨가된 $\mathrm{CoCrFeMnNiC} \mathrm{C}_{0.1}$

합금이 탄소가 첨가되지 않은 $\mathrm{CoCrFeMnNi}$ 합금 보다 크게 측정되나, $900{ }^{\circ} \mathrm{C}$ 와 $1,000{ }^{\circ} \mathrm{C}$ 로 열처리 온도가 증가 함에 따라 탄소가 첨가되지 않은 $\mathrm{CoCrFeMnNi}$ 합금의 연 신율이 탄소가 첨가된 $\mathrm{CoCrFeMnNiC}_{0.1}$ 합금보다 크게 측 정되었으며, 이는 열처리 온도 증가에 따른 미세구조의 변 화와 연관된다.

그림 7 는 $\mathrm{CoCrFeMnNi}$ 합금과 $\mathrm{CoCrFeMnNiC}_{0.1}$ 합금 


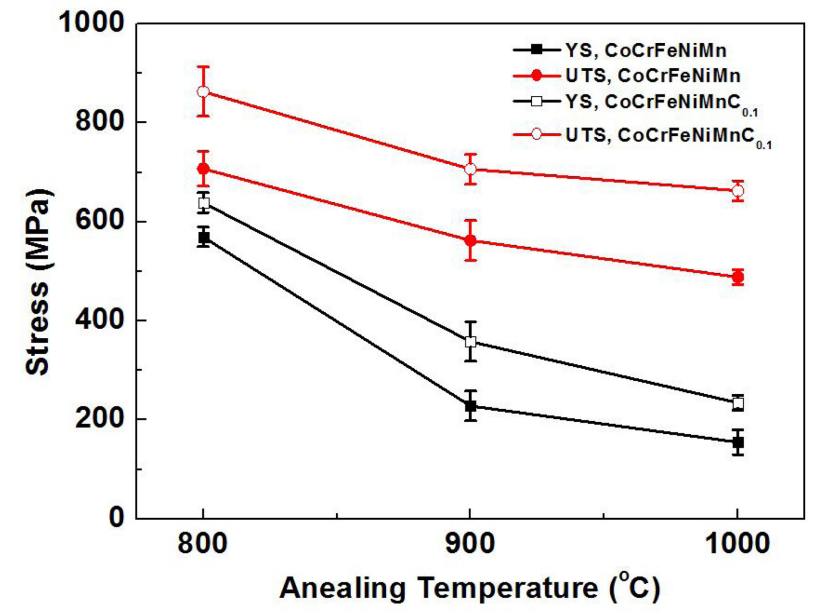

Fig. 7. UTS and YS of the CoCrFeMnNi and $\mathrm{CoCrFeMnNiC0.1}$ alloy plotted as a function of temperature.

을 냉간압연 후 $800{ }^{\circ} \mathrm{C}, 900{ }^{\circ} \mathrm{C}, 1,000{ }^{\circ} \mathrm{C}$ 에서 2 시간 열처 리 후의 열처리 온도에 따른 항복강도와 인장강도의 변화 를 나타내었다. 그림 6 의 응력-변형율 곡선에 나타난 바와 같이 탄소가 첨가된 $\mathrm{CoCrFeMnNiC}_{0.1}$ 합금의 강도는 모든 열처리 온도에서 $\mathrm{CoCrFeMnNi}$ 합금의 강도보다 높게 측정 되었다. 열처리 온도가 $800{ }^{\circ} \mathrm{C}$ 이상으로 증가함에 따라 강 도가 감소하는 폭 또한 커지는 것은 위에서 설명한 바와 같 다. $\mathrm{CoCrFeMnNiC}_{0.1}$ 합금의 강도가 $\mathrm{CoCrFeMnNi}$ 합금보 다 큰 이유 는 전술한 바와 같이 대부분이 고용된 탄소와 탄화물의 전위 이동에 대한 저항응력 (friction stress)의 증 가로 감소 지연 효과는 탄화물들이 고온에서 결정립 성장 을 지연시켜 나타나는 것으로 판단된다. 실제로 Stepanov 등 [14]과 Otto 등 [16]은 스테인레스강, TWIP강, 고엔트로 피 합금에서 결정립이 $10 \mu \mathrm{m}$ 에서 $5 \mu \mathrm{m}$ 로 감소할 때, 강도 가 8 18 MPa 정도 증가한다고 보고하였다. 그림 7에 나 타난 바와 같이 탄소첨가에 의하여 강도가 $100 \sim 150 \mathrm{MPa}$ 증가하였으며, Stepanov 등 [14]과 Otto 등 [16]이 보고한 결정립 감소에 의한 강도 증가 크기보다 훨씬 크므로, 본 연구에서도 탄소첨가에 의한 결정립 크기의 감소가 강도 증진에 미치는 영향은 크지않은 것으로 판단된다. 따라서 본 연구에서 탄소첨가에 의한 강도증진 효과는 대부분 이 탄소첨가에 의한 직접적인 효과, 즉 고용탄소와 탄화물에 의한 효과이며, 강도증진의 $10 \%$ 내외는 탄소 첨가에 의한 결정립 감소에 의한 것으로 판단된다.

그림 8 은 탄소가 첨가되지 않은 $\mathrm{CoCrFeMnNi}$ 합금과 탄소가 첨가된 $\mathrm{CoCrFeMnNiC}$. 합금의 변형율에 따른 가 공경화율의 변화를 보여주고 있다. 탄소가 첨가된 $\mathrm{CoCrFeMnNiC}{ }_{0.1}$ 합금의 경우 $800{ }^{\circ} \mathrm{C}$ 에서 열처리한 경우

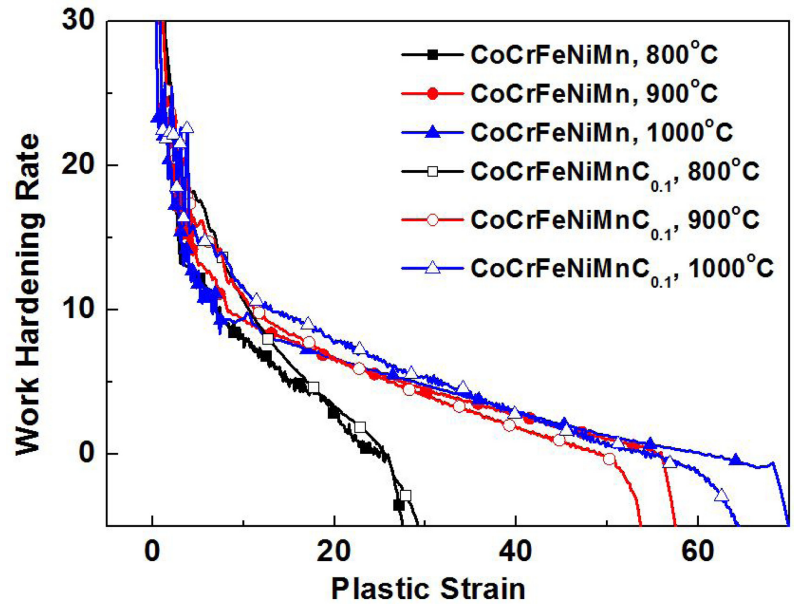

Fig. 8. Work Hardening Rate of the $\mathrm{CoCrFeMnNi}$ and $\mathrm{CoCrFeMnNiC} 0.1$ after cold rolling and subsequent annealing at $800{ }^{\circ} \mathrm{C}, 900{ }^{\circ} \mathrm{C}, 1000{ }^{\circ} \mathrm{C}$ for $2 \mathrm{hrs}$.

에 전 구역에서 $\mathrm{CoCrFeMnNi}$ 합금보다 가공경화율이 눈에 띄게 높음을 보여주고 있다. $900{ }^{\circ} \mathrm{C}, 1,000{ }^{\circ} \mathrm{C}$ 에서 열처리후 에는 $\mathrm{CoCrFeMnNiC}_{0.1}$ 합금이 $\mathrm{CoCrFeMnNi}$ 합금보다 강 도는 높지만 탄소 첨가에 의한 가공경화율의 차이는 크지 않음을 알 수 있다. 이는 완전재결정 후의 탄소첨가에 의 한 강화는 전위의 이동에 저항응력 (friction stress) 효과의 기여가 주요 강화원인임을 강력하게 뒷받침한다 [17-19,2527]. 이러한 저항응력은 탄화물의 강도, 전위 밀도, 결정립 크기 등 여러 가지 요인이 있을 수 있지만, 전술한 바와 같이 탄소 및 탄화물에 의한 결정립 미세화의 강도 증가분 은 본 연구에서 관찰되는 강도 증가 크기에 비하여 작고, 또한 큰 탄화물과 같은 강한 방해물이 있을 때 관찰되는 변형율에 따른 가공경화속도의 증가가 관찰되지 않으므로, 따라서 앞에 제시한 탄소나 미세한 탄화물에 의한 마찰 응력 증가가 주된 강도증진 기구임을 강력하게 뒷받침한다. $800{ }^{\circ} \mathrm{C}$ 시 열처리시 탄소가 첨가된 $\mathrm{CoCrFeMnNiC}$. 합금에 서 연성 증가는 가공경화속도의 증가와 연관된다. $\mathrm{CoCrFeMnNiC}_{0.1}$ 합금에서 변형에 따른 경화속도의 증가는 $\mathrm{CoCrFeMnNi}$ 합금의 변형보다 더 균일한 변형이 일어나기 때문이다 [6]. 또한 기지내에 존재하는 탄화물들이 높은 가 공율과 열처리에 의하여 부분적으로 기지에 재용해 되고 용질-전위 상호작용에 의하여 경화속도에 기여하였기 때 문으로 여겨진다 [14-20,26]. 반면에 $900{ }^{\circ} \mathrm{C}, 1,000{ }^{\circ} \mathrm{C}$ 에 서 열처리 후에는 $\mathrm{CoCrFeMnNiC}_{0.1}$ 합금의 가공경화 속 도가 $\mathrm{CoCrFeMnNi}$ 합금보다 초기에는 낮지만, $30 ~ 40 \%$ 변형율에서 $\mathrm{CoCrFeMnNiC}_{0.1}$ 합금의 가공경화속도가 $\mathrm{CoCrFeMnNi}$ 합금보다 낮아지며, 이러한 고변형율에서의 가공경화 속도의 저하가 $\mathrm{CoCrFeMnNiC}_{0.1}$ 합금의 연성이 
$\mathrm{CoCrFeMnNi}$ 합금보다 낮아지는 원인이다.

\section{4. 결 론}

$\mathrm{CoCrFeMnNi}$ 합금과 탄소가 첨가된 $\mathrm{CoCrFeMnNiC} 0.1$ 합금에 대한 탄소첨가 영향을 평가한 결과 다음과 같은 결 론을 얻었다.

1. $\mathrm{CoCrFeMnNi}$ 합금과 탄소가 첨가된 $\mathrm{CoCrFeMnNiC} 0.1$ 합금 모두 주조 후 미세구조는 덴드라이트 구조를 나타내 며, 탄소가 첨가된 $\mathrm{CoCrFeMnNiC}_{0.1}$ 합금의 경우 덴드라 이트 사이 (inter-dendric region)에 $\mathrm{Cr}$ 탄화물이 석출하였다.

2. $1,050{ }^{\circ} \mathrm{C}$ 에서 24 시간 균질화 처리 후 연신된 형태의 결정립은 덴드라이트 구조에서 primary arm의 방향과 연 관되며, 이는 주조 시에 덴드라이트 사이 (inter-denditic region)에 편석된 $\mathrm{Cr}$ 탄화물이 재결정 성장에 영향을 주기 때문이다. 탄소가 첨가된 $\mathrm{CoCrFeMnNiC}_{0.1}$ 합금에서 탄화 물은 결정입계에 편석되어 결정립 성장을 방해하며, 결정 입계에 존재하는 석출물은 $\mathrm{Cr}$-rich 탄화물로 분석되었다.

3. $800{ }^{\circ} \mathrm{C}$ 에서 2 시간 열처리 한 $\mathrm{CoCrFeMnNi}$ 합금과 $\mathrm{CoCrFeMnNiC}_{0.1}$ 합금에서 냉간 가공 중 발달한 변형대는 관찰되지 않으나 미세한 입자들이 불균일하게 분포하고 있 다. 일부 구역에서 작은 결정립과 twin 밴드가 관찰되는데, 이는 $800{ }^{\circ} \mathrm{C}$ 에서는 국부적인 재결정이 일어나며, 따라서 전 반적인 재결정을 위해서는 더 높은 온도에서 열처리해야 됨을 나타낸다.

4. $900{ }^{\circ} \mathrm{C}$ 와 $1,000{ }^{\circ} \mathrm{C}$ 에서 $\mathrm{CoCrFeMnNi}$ 합금과 $\mathrm{CoCrFeMnNiC}_{0.1}$ 합금 모두 재결정으로 인한 결정립 구조 를 나타내며, $\mathrm{CoCrFeMnNiC} 0.1$ 합금의 결정립이 미세하게 관찰되었으며, 탄소가 첨가된 $\mathrm{CoCrFeMnNiC} \mathrm{C}_{0.1}$ 합금이 $\mathrm{CoCrFeMnNi}$ 합금보다 열처리에 따른 결정립 의 크기가 작게 관찰되며, 이는 탄소 또는 탄화물 형성이 결정립 감 소의 직접적인 원인임을 의미한다.

5. 본 연구에서 탄소첨가에 의한 강도증진 효과는 대부 분이 탄소첨가에 의한 직접적인 효과, 즉 고용탄소와 탄화 물에 의한 효과이며, 탄소 첨가에 의한 결정립 감소에 의 한 강도증진 효과는 탄소첨가에 의한 직접적인 강도증진 효과보다 훨씬 작은 것으로 판단된다.

\section{ACKNOWLEDGMENTS}

This research was supported by the Future Material Discovery Program of the National Research Foundation of Korea (NRF) funded by the Ministry of
Science, ICT and Future Planning (MSIP) of Korea (2016M3D1A1023532).

\section{REFERENCES}

1. N. D. Stepanov, N. Yu. Yurchenko, M. A. Tikhonovsky, and G. A. Salishchev, J. Alloy. Compd. 687, 59 (2016).

2. J. W. Yeh, S. K. Chen, S. J. Lin, J. Y. Gan, T. S. Chin, T. T. Shun, C. H. Tsau, and S. Y. Chang, Adv. Eng. Mater. 6, 299 (2004).

3. F. Otto, A. Dlouhy, Ch. Somsen, H. Bei, G. Eggeler, and E. P. George, Acta Mater. 61, 5743 (2013).

4. C. J. Tong, M. R. Chen, S. K. Chen, J. W. Yeh, T. T. Shun, S. J. Lin, and S. Y. Chang, Metall. Mater. Trans. A 36, 1263 (2005).

5. B. S. Murty, J.-W. Yeh, and S. Ranganathan, High-Entropy Alloys $1^{\text {st }}$ ed., pp.133-148, Butterworth-Heinemann, United Kimdom (2014).

6. S. I. Hong, J. Moon, S. K. Hong, and H. S. Kim, Mat. Sci. Eng. A 682, 569 (2017).

7. T. Liyanage, G. Fisher, and A. P. Gerlich, Surf. Coat. Tech. 205, 759 (2010).

8. K. A. Al-Jarba and G. E. Fuchs, JOM 56, 50 (2004)

9. J. I. Lee, H. S. Oh, J. H. Kim, and E. S. Park, Korean J. Met. Mater. 55, 1 (2017).

10. M. J. Jang, S. H. Joo, C. W. Tsai, J. W. Yeh, and H. S. Kim, Met. Mater. Int. 22, 982 (2016).

11. H. J. Park, Y. S. Na, S. H. Hong, J. T. Kim, Y. S. Kim, K. R. Lim, J. M. Park, and K. B. Kim, Met. Mater. Int. 22, 551 (2016).

12. S. Y. Ahn, J. S. Song, and S. I. Hong, Korean J. Met. Mater. 55, 477 (2017).

13. I. Sah, J. B. Hwang, S. I. Hong, E. S. Kim, and M. H. Kim, Korean J. Met. Mater. 55, 115 (2017).

14. N. D. Stepanov, D. G. Shaysultanov, R. S. Chernichenko, N. Yu. Yurchenko, S. V. Zherebtsov, M. A. Tikhonovsky, and G. A. Salishchev, J. Alloy. Compd. 693, 394 (2017).

15. P. P. Bhattacharjee, G. D. Sathiaraj, M. Zaid, J. R. Gatti, C. Lee, C. W. Tsai, and J. W. Yeh, J. Alloy. Compd. 587, 544 (2014).

16. F. Otto, A. Dlouhy, C. Somsen, H. Bei, G. Eggeler, and E. P. George, Acta Mater. 61, 5743 (2013).

17. S. I. Hong, G. T. Gray III, and J. J. Lewandowski, Acta Metall. Mater. 41, 2337 (1993).

18. S. I. Hong and C. Laird, Acta Metall. 38, 1581 (1990).

19. U. F. Kocks, Metall. Mater. Trans. A 16, 2109 (1985). 
20. H. S. Kim, S. I. Hong, and M. H. Seo, J. Mater. Res. 16, 856 (2001).

21. S. I. Hong, G. T. Gray, and J. J. Lewandowski, Acta Metal. Mater. 41, 2337 (1993)

22. I. K. Kim and S. I. Hong, Mater. Design 47, 590 (2013).

23. I. K. Kim and S. I. Hong, Mater. Design 49, 935 (2013).

24. S. I. Hong, Scripta Mater. 44, 995 (2001).
25. K. I. Chang and S. I. Hong, J. Nucl. Mater. 373, 16 (2008). 26. J. Y. Ko, S. M. Oh, Y. B. Gang, S. Y. Ahn, J. S. Song, S. K. Hong, G. H. Lee, N. G. Park, and S. I. Hong, Trends in Met. \& Mater. Eng. 30, 1 (2017).

27. J. Moon, S. I. Hong, J. W. Bae, M. J. Jang, D. Yim, and H. S, Kim, Mater. Res. Lett. 6, 312 (2017). 